\title{
A new species of Ingolfiellidae (Peracarida, Amphipoda, Crustacea) from the Azores, Portugal
}

\author{
M. Rubal $\cdot$ K. Larsen
}

Received: 20 December 2011/Revised: 2 May 2012/Accepted: 17 May 2012/Published online: 12 June 2012

(C) Springer-Verlag and AWI 2012

\begin{abstract}
A new species of Ingolfiellid Amphipod Ingolfiella azorensis $\mathrm{n}$. sp. is described from samples collected in a benthic survey off the Azores archipelago, Portugal. The new species is characterized by the lack of ocular lobes, a four-toothed dactylus on the first and second gnathopods, and having dissimilar claws on the third to seventh pereiopods. Individuals were obtained from shallow subtidal samples of sand. The new findings bring the number of Ingolfiellidae from Macaronesia up to six, equalling almost $20 \%$ of the world's known species, suggesting this area as a potential evolutionary centre for Ingolfiellidae.
\end{abstract}

Keywords Crustacea $\cdot$ Ingolfiellidae $\cdot$ Ingolfiella azorensis n. sp. A Atlantic · Macaronesia - Shallow subtidal

\section{Introduction}

The amphipod suborder Ingolfiellidea includes only two families (Metaingolfiellidae and Ingolfiellidae), six genera, and 40 species. Little is known about the phylogeny of

Communicated by Heinz-Dieter Franke.

M. Rubal

LBC (Laboratory of Coastal Biodiversity),

CIIMAR (Centro Interdisciplinar de Investigação Marinha e

Ambiental), Rua dos Bragas 289, 4050-123 Porto, Portugal

e-mail: mrubal@ciimar.up.pt

K. Larsen $(\square)$

LMCEE (Laboratory of Marine Community Ecology and

Evolution), CIIMAR (Centro Interdisciplinar de Investigação

Marinha e Ambiental), Rua dos Bragas 289,

4050-123 Porto, Portugal

e-mail: tanaids@hotmail.com
Ingolfiellidae, and there is little consensus regarding the systematics. Stock (1976) and Ruffo and Vigna Taglianti (1989) suggested a division into eight subgenera, but this systematic classification is heavily dependent on characters of both sexes that are often not available; therefore, this view has been contested by several specialists (Dojiri and Sieg 1987; Lowry and Poore 1989; Vonk and Sanchez 1991). A phylogenetic analysis to the suborder was conducted by Vonk and Schram (2003a, b), while Berge et al. (2000) claim the order is not monophyletic.

Since the first species of ingolfiellidean was described by Hansen (1903), species of this group has been found in the deep sea, over shallow water, brackish water, fresh water, and hypogean habitats (Lowry and Poore 1989). Despite the wide range of habitats that ingolfiellideans can inhabit, only a low number of species are recognized (Vonk and Schram 2003a). This can be explained by their mainly interstitial habitat, usually found in environments difficult to sample, such as the deep sea, deep subsurface of coastal sediments, hypogean habitats, or riverbanks. Additionally, females and males of the same species are only known for 13 of the 28 species of the most common genus Ingolfiella (Senna and Serejo 2005).

During a benthic survey at São Miguel Island (Azores, Portugal), four male individuals ingolfiellid were collected and described as Ingolfiella azorensis n. sp. in this paper. They were found in a relatively accessible habitat (marine sediments, $10-15 \mathrm{~m}$ depth, in the upper $10 \mathrm{~cm}$ of the sediment). This is the first record of the genus from the Azores archipelago. This lack of data about this genus in the Azores is divergent with the relatively abundant data of Ingolfiella at other Macaronesian archipelagos like Madeira (Stock 1992; Andres 2005), Canary Islands (Rondé-Broekhuizen and Stock 1987; Vonk and Sanchez 1991), and Selvagen Islands (Larsen unpublished data). 


\section{Materials and methods}

Specimens of the new species were collected at Pisão $\left(37^{\circ} 42^{\prime} 26.13^{\prime \prime} \mathrm{N} ; 25^{\circ} 30^{\prime} 22.17^{\prime \prime} \mathrm{W}\right)$ and São Roque $\left(37^{\circ} 44^{\prime}\right.$ $51.23^{\prime \prime} \mathrm{N} ; 25^{\circ} 37^{\prime} 57.77^{\prime \prime} \mathrm{W}$ ), both located in the south of São Miguel Island (Azores), within the framework of a benthic sampling programme in 2008. Sampling was done on clean sand at $10-12 \mathrm{~m}$ depth by SCUBA divers operating manual push-corers $(10 \mathrm{~cm}$ diameter and $10 \mathrm{~cm}$ depth). Collected sediment was put in individual labelled plastic bags and transported to the laboratory. Samples were later fixed in $5 \%$ formaldehyde and then sieved through a column of $0.5 \mathrm{~mm}$ and $0.063-\mu \mathrm{m}$ nested sieves and the residue placed in plastic buckets. Animals retained on the $0.5-\mathrm{mm}$ mesh were sorted under a dissection stereomicroscope and preserved in $70 \%$ ethanol until identification.

Line drawing of the holotype and one dissected adult male was done with a compound microscope with attached camera lucida. Dissections were made in glycerine using chemically sharpened tungsten-wire needles. Body total length (TL) was measured from the tip of the cephalothorax to the apex of the pleotelson. The terminology in the descriptions is based on Vonk and Schram (2003a, b). The type material is deposited in Museum Municipal do Funchal (História Natural), Madeira.

\section{Results}

Family Ingolfiellidae Hansen 1903

Genus Ingolfiella Hansen 1903

Ingolfiella azorensis $\mathrm{n}$. sp.

Type material Holotype: ô TL 1.3 mm, Pisão. Paratypes: 3 วิึิ São Roque (one dissected).

Type locality São Miguel Island, Azores (Portugal).

Etymology Named after the Azores archipelago where the specimens were found.

Diagnosis Body slender. Pereionites, pleonites, urosomites, and telson with dorsal setae. Head without rostrum or developed ocular lobes. Accessory flagellum of first antenna consisting of three segments. Gnathopod 1: carpus slender; palm of carpus nearly straight, with nine setae; dactylus with four teeth. Gnathopod 2: carpus broad, about 1.8 times as long as wide, with some minute teeth, one long palmar angle spine, one short robust seta, and seven slender setae on margin; dactylus with four teeth. Pereiopods 3-7 dactyli dissimilar. Pereiopods 3 and 4: dactylus slender and long; distally trifid. Pereiopods 5-6: dactylus moderately robust, distally bifid. Pereiopod 7 longer than other pereiopods dactylus robust, distally bifid. Gills observable on pereiopods 3-5. Pleopods 1-3 uniramous, subspherical. Uropod 1 biramous, slightly longer than uropod 2; secondary sexual character consists of a small latero-subdistal pedestal bearing one long, strong terminally dichotomous seta. Endopod with a row of four setae dorsally and apex with three stout distal setae. Uropod 2 biramous with three rows of short stout setae on the lateral surface. Uropod 3 small, uniramous. Telson fleshy.

\section{Description of the male holotype Reg \# MMF42262}

Body TL $1.3 \mathrm{~mm}$. Scattered fine setae dorsolaterally (recognized on pereionites 1, 3-4; pleonite 3 , urosomite 2 and telson). Body elongate, laterally compressed (Fig. 1a). Head as long as free peraeonite 1; rostrum and ocular lobes absent (Fig. 1a). Peraeonite 1 as deep as long; ventrolateral margin oblique, deeper anteriorly. Pereionites 2-7 subrectangular, as long as deep. Pleonites 1-3 a little deeper than long, subequal. Urosomites 1-2 subtrapezoidal, Ul as long as U2, both deeper than long; U3 longer than deep.

Antenna 1 (Fig. 1b) 1.25 times as longer as the A2 (ventral margin). Peduncle article 11.33 times as long as head, longer than peduncle articles 2 and 3 combined; article ratios (ventral margin) 1.0:0.38:0.13. Accessory flagellum (Fig. 1c) three-articled, reaching end of flagellum article 1; article ratios (ventral margin) 1.0:3.3:0.97; article 1 naked; article 2 with one seta distally; article 3 with two apical setae. Flagellum five-articled, 0.83 times shorter in length than basal peduncle article; article ratios (ventral margin) 1.0:1. 85:1.41:1.52:0.63; article 4 with one small aesthetasc at tip.

Antenna 2 (Fig. 1d) Peduncle subequal to A1 peduncle; articles 2-4 subequal. Flagellum five-articled, 0.67 times shorter in length than peduncle articles 1 and 2 combined.

Maxilliped (Fig. 1e) Bases not fused proximally; endite on basis only bearing one apical setae. Palp five-articled; article ratios (ventral margin) 1.0:0.78:0.82:0.6:0.38, medial setation formula of articles 1-4:3:1:1:1; article 5 with long, falcate unguis and one strong seta basal to unguis; lateral propodal setal row not recognized.

Gnathopod 1 (Fig. 2a) Coxa small, subrectangular, inserted anteriorly in peraeonite. Basis longer than ischium and merus combined, bearing one slender seta on the posterior margin. Ischium smaller than merus, with one slender seta on posterior margin. Merus slender, with two slender seta on posterior margin. Carpus elongate, suboval; length (anterior margin) 2.4 times as maximal width; posterior margin bearing two stout setae; palm oblique with four stout and two slender proximal setae and two distal slender setae. Propodus narrow with a two posterior slender setae. Dactylus with four elongate spines. 
Fig. 1 I. azorensis n. sp. holotype male (1.3 $\mathrm{mm} \mathrm{TL})$ : a habitus, b antenna 1 ,

c accessory flagellum of antenna 1 , d antenna 2, e maxilliped, f uropod $1, \mathbf{g}$ uropod 2. Scale bars $=0.5 \mathrm{~mm}$

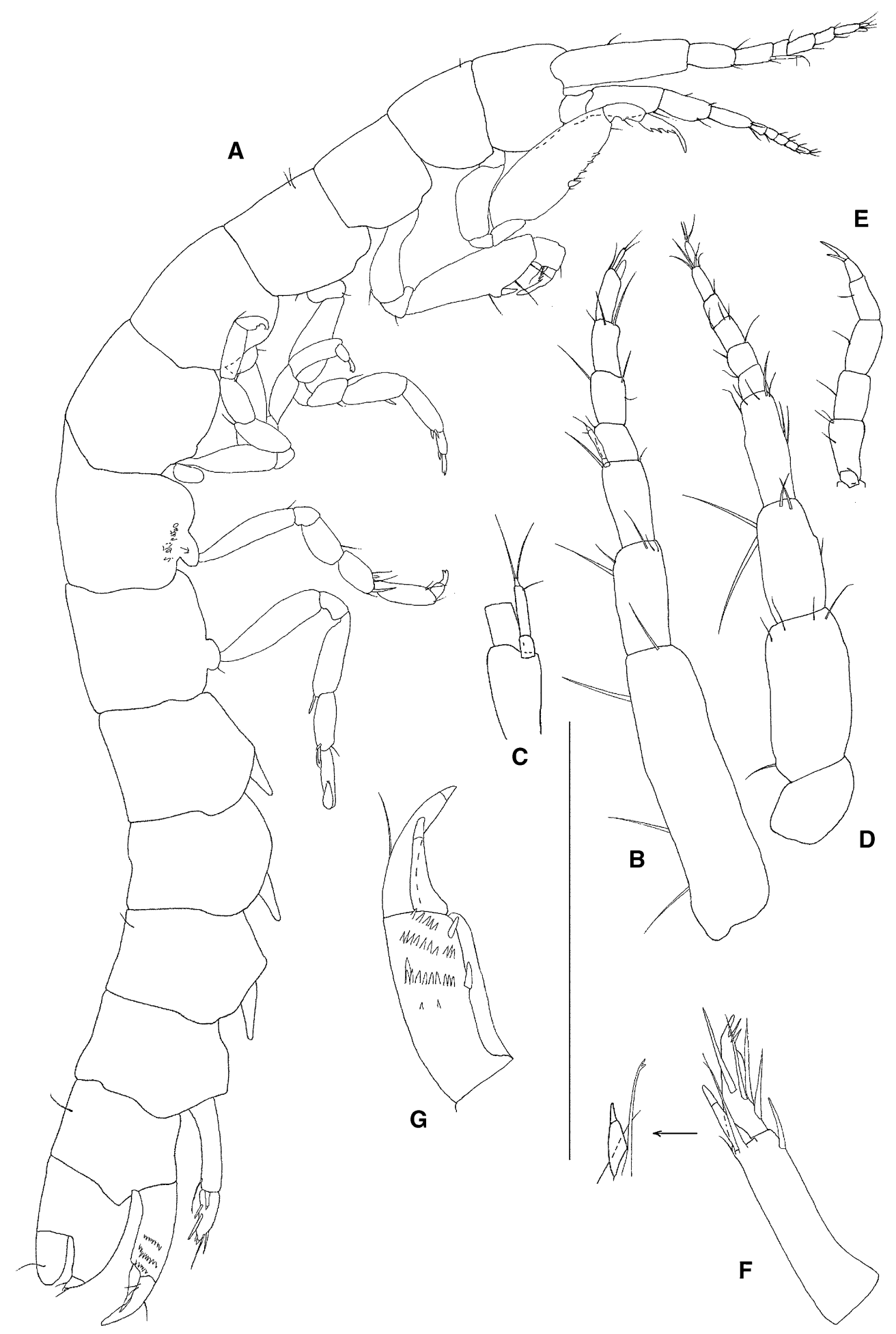

Gnathopod 2 (Fig. 2b) Coxa small, subrectangular, inserted anteriorly in peraeonite. Basis longer than ischium and merus combined, bearing one slender seta on posterior margin. Ischium smaller than merus, with one slender seta on posterior margin. Merus slender, with two slender seta on posterior margin. Carpus elongate, suboval, length (anterior margin) 1.8 times as maximal width. Posterior margin bearing two distal slender setae; a distal depression parallel to palm; palm oblique with two stout setae and seven slender setae. Propodus narrow with two posterior slender setae. Dactylus with four elongate spines.

Peraeopod 3 (Fig. 2c) P3 inserted midway in peraeonite; coxae subrectangular, bearing one anterior slender seta. 
Fig. 2 I. azorensis n. sp. holotype male (1.3 $\mathrm{mm} \mathrm{TL}$ ): a gnathopod 1 , b gnathopod 2 , c peraeopod 3, d peraeopod 4, e peraeopod 5 , f peraeopod 6 , g peraeopod 7 , h pleopod. Scale bars $=0.5 \mathrm{~mm}$

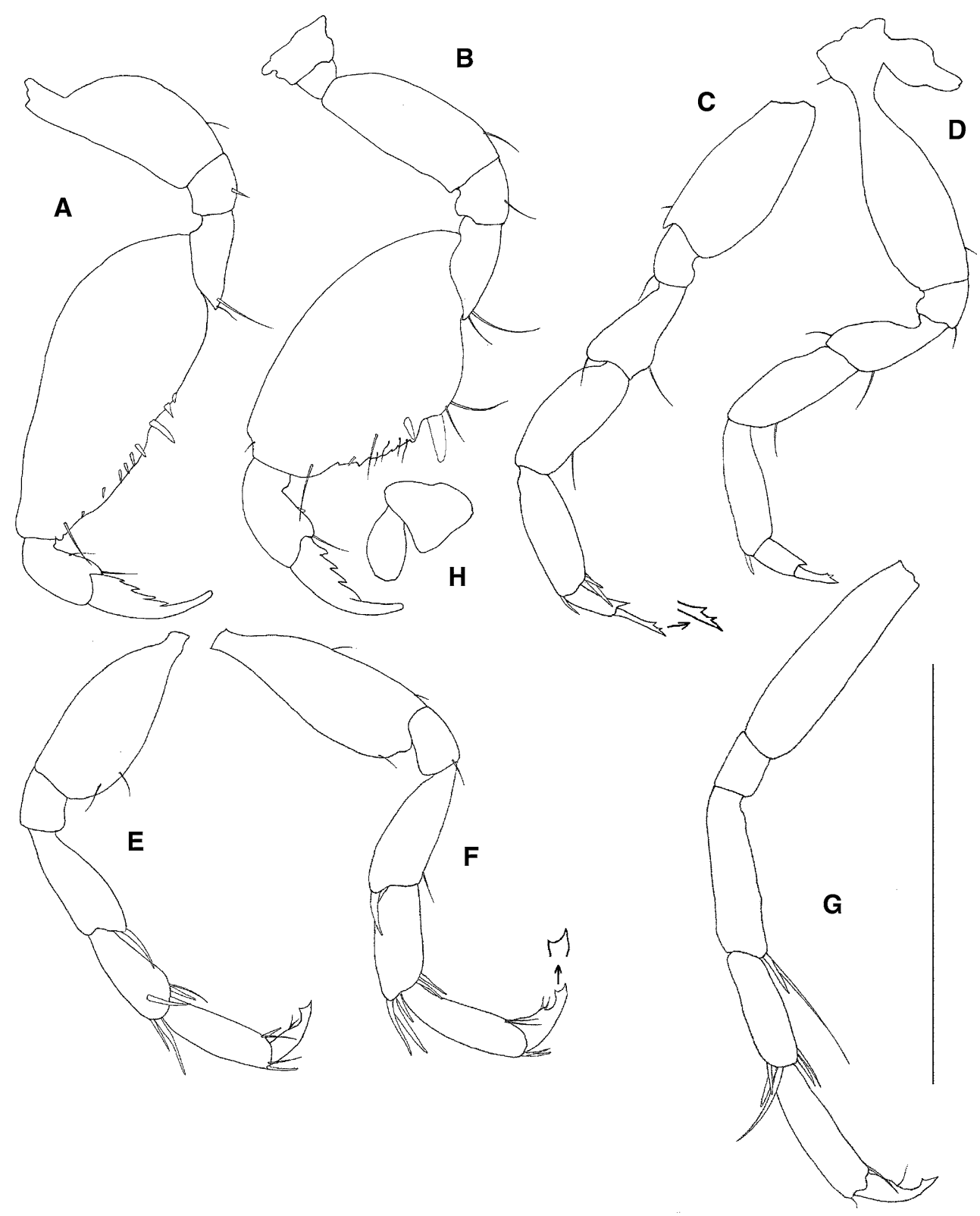

Basis slightly widened distally, about as long as merus and carpus combined; with one anterior slender seta. Ischium bearing one anterior slender seta. Merus bearing one anterior and one posterior slender seta. Carpus bearing one posterior slender seta. Propodus bearing one anterodistal and two posterodistal slender setae. Dactylus carrying a strong posterodistal spine and a trifid claw.

Peraeopod 4 (Fig. 2d) P4 inserted midway in the peraeonite; coxae subrectangular bearing one anterior slender seta. Basis slightly widened distally, about as long as merus and carpus combined; with one posterior slender seta. Ischium bearing one posterior slender seta. Merus bearing one anterior and one posterior slender seta. Carpus bearing one posterior slender seta. Propodus bearing one anterodistal slender seta. Dactylus carrying a strong posterodistal spine and a trifid claw.

Peraeopod 5 (Fig. 2e) P5 inserted midway in the peraeonite; coxae subrectangular. Basis slightly widened distally, about as long as merus and carpus combined bearing two posterior slender setae. Ischium without seta. Merus bearing one posterior stout seta. Carpus bearing two stout and one slender anterodistal setae and two posterodistal slender setae. Propodus bearing two anterodistal and two posterodistal slender seta. Dactylus carrying two slender distal setae and stout curved bifid claw.

Peraeopod 6 (Fig. 2f) P6 inserted midway in the peraeonite; coxae subrectangular. Basis slightly widened distally, 
about as long as merus and carpus combined bearing two posterior setae and one anterior slender seta. Ischium with one posterior slender seta. Merus bearing one posterior slender seta and one anterior stout seta. Carpus bearing three stout anterodistal setae and two posterodistal slender setae. Propodus bearing two anterodistal and two posterodistal slender setae. Dactylus carrying two slender distal setae and stout curved bifid claw.

Peraeopod 7 (Fig. 2g) P7 inserted midway in peraeonite; coxae subrectangular, bearing a slender posterior seta. Basis about as long as merus and carpus combined. Ischium without setae. Merus bearing one slender and one stout posterior setae. Carpus bearing three stout anterodistal setae and two posterodistal slender setae. Propodus bearing one anterodistal and one posterodistal slender setae. Dactylus carrying one slender distal setae and stout curved bifid claw.

Gills on pereiopods 3-5.

Pleopods (Fig. 2h) Pleopods 1-3 present, uniramous; P1-2 subspherical in shape..

Uropod 1 (Fig. 1f) Peduncle biramous, with a distal posterior slender seta, exopod thinner and shorter than endopod. By the exopod basis a peduncle with sexually character consisting of a small latero-subdistal, pedestal bearing one long, strong terminally dichotomous seta and a few denticles subapically (Fig. 1b). Endopod with a row of four setae dorsally and apex with three stout distal setae.

Uropod 2 (Fig. 1g) Peduncle biramous, with two distal short stout setae, three rows of short stout setae on lateral surface. Exopod with a long slender seta and slightly longer than endopod.

Uropod 3 (Fig. 1a) Small, uniramous, bi-articulated peduncle with one dorsal and one ventral slender setae.

Telson Fleshy, with a dorsal slender seta.

Intraspecific variation. The major difference among the holotype and the paratypes was the number and position of the body dorsal setae. The number and position of these body setae are very variable among the studied individuals.

\section{Remarks}

The more noticeable differential character of I. azorensis $\mathrm{n}$. sp. with respect to other marine species of this genus is the absence of the ocular lobe. This feature is common in species from riverbanks, wells, or hypogean habitats (e.g. I. petkovskii Karaman 1957, I. macedonica Karaman 1959, I. catalanensis Coineau 1963, and I. uspallatae Noodt 1965), but this is the first fully marine species with this character. Within the genus Ingolfiella, I. azorensis $\mathrm{n}$. sp. is closely related to the group of species possessing a fourtoothed dactylus on the first and second gnathopod and having dissimilar claws on the third to seventh pereiopods. The morphology of the new species is close to I. canarensis Vonk and Sanchez 1991 and I. fuscina Dojiri and Sieg 1987, but I. azorensis n. sp. differs from I. canarensis by the lack of the ocular lobe, the absence of basal hookshaped spine on the peduncle of the second uropod, and the presence of the latero-subdistal pedestal bearing one long, strong, terminally dichotomous seta. Ingolfiella azorensis n. sp. differs from I. fuscina by the lack of the ocular lobe, the presence of dorsal setae on the body, and the presence of three rows of spines on lateral surface of the uropod 2 instead of the four ones found on I. fuscina. Other morphologically close species are I. kapuri Coineau and Rao 1972 and I. quadridentata Stock 1979. Ingolfiella azorensis n. sp. differs from these two species in having a serrate gnathopod 2 palm that is not serrate and lacking an ocular lobe. Furthermore, I. azorensis n. sp. also differs from I. inermis Shimomura, Ohtsuka, and Tomikawa 2006 in lacking an ocular lobe and in having dorsal setae on the body and a bifid dactylus on pereiopods 5-7. Finally, I. longipes Stock, Sket and Iliffe 1987, and I. sandroruffoi Andres 2004 differ from I. azorensis n. sp. by the presence of ocular lobe, serration on the palmar margin of gnatopod 2 , and the bifid dactylus of the pereiopods 3 and 4 , which are trifid in I. azorensis n. sp.

With the description of I. azorensis n. sp. from São Miguel Island, the distribution of Ingolfiellidae is extended to the waters off the Azores archipelago. An additional species was collected from the Selvagen Islands (South of Madeira), at $41^{\circ} 41^{\prime} \mathrm{N}, 08^{\circ} 51^{\prime} \mathrm{W}$, but the specimen was subsequently lost. The new findings bring the number of Ingolfiellidae from Macaronesia up to six, equalling almost $20 \%$ of the world's known species, suggesting this area as a potential evolutionary centre for Ingolfiellidae. Similarly to Macaronesia, there are 3 described (Lowry and Poore 1989; Gallego-Martínez and Poore 2003) and 2 undescribed species in Australian waters (Anonymous reviewer, pers. com.), which have also been proposed as an evolutionary centre for amphipods (Barnard and Karaman 1983). However, more research effort is needed to define an evolutionary centre because (1) Ingolfiellidae is a very diverse group that shows a disjoint distribution pattern (Andres 2004) and (2) the high diversity and restricted local distribution of Ingolfiellidae is probably the result of its limited ability to disperse since Ingolfiellidae lack well-developed pleopods and dispersal stages (Andres 2004). Therefore, the high number of species of Ingolfiellidae found at Macaronesia or Australia could merely reflect sampling effort rather than their role as evolutionary centres. For example, have a new species of deep-sea Ingolfiellidae just been found in the middle of the Pacific (Larsen, unpublished data). 
Acknowledgments We are grateful to J. Santos and Dr. G. Martins for providing the studied material from the Azores and Dr. P. Veiga for her help and comments on early versions of the manuscript. We are grateful to Drs. L. Sampaio and R. Vonk for provide us valuable bibliographical references. We are also grateful to two anonymous referees for all the helpful comments and suggestions, which greatly improved this paper.

\section{References}

Andres HG (2004) Ingolfiella sandroruffoi sp. nov. (Crustacea: Amphipoda: Ingolfiellidae) from the Great Meteor Seamount (North-eastern Atlantic Ocean). Mitt Hamb Zool Mus Inst 101:225-236

Andres HG (2005) Ingolfiella georgei sp. nov. (Crustacea, Amphipoda, Ingolfiellidae) recorded from the Atlantic Seine seamount north east of Madeiran Islands. Mitt Hamb Zool Mus Inst 102:71-84

Barnard JL, Karaman GS (1983) Australia as a major evolutionary centre for Amphipoda (Crustacea). Mem Austr Mus 18:45-61

Berge J, Boxshall G, Vader W (2000) Phylogenetic analysis of the Amphipoda, with special emphasis on the origin of the Stegocephalidae. Pol Arch Hydrobiol 47:379-400

Dojiri M, Sieg J (1987) Ingolfiella fuscina, new species (Crustacea: Amphipoda) from the Gulf of Mexico and the Atlantic coast of North America, and partial redescription of I. atlantisi Mills, 1967. Proc Biol Soc Wash 103:494-505

Gallego-Martínez S, Poore CB (2003) A new species of ingolfiellid amphipod (Crustacea: Amphipoda) from western Australia. Rec Western Australian Mus 22:75-80
Hansen HJ (1903) The Ingolfiellidae, fam. n., a new type of Amphipoda. J Linn Soc Lond 29:117-133

Lowry JK, Poore CB (1989) First ingolfiellids from the Southwest Pacific (Crustacea: Amphipoda) with a discussion of their systematics. Proc Biol Soc Wash 102:933-944

Rondé-Broekhuizen B, Stock JH (1987) Stygofauna of the Canary Islands, 2: a new ingolfiellid (Crustacea, Amphipoda) with West Indian affinities from the Canary Islands. Arch Hydrobiol 110:441-450

Ruffo S, Vigna Taglianti A (1989) Description of a new cavernicolous Ingolfiella species from Sardinia, with remarks on the systematics of the genus (Crustacea, Amphipoda, Ingolfiellidea). Ann Mus Civ Stor Nat Genova 87:237-261

Senna AS, Serejo C (2005) Ingolfiella rocaensis sp. nov. (Crustacea: Amphipoda: Ingolfiellidea): first record of ingolfiellidean amphipods in Brazilian waters. Zootaxa 962:1-6

Stock JH (1976) A new member of the crustacean suborder Ingolfiellidea from Bonaire, with a review of the entire suborder. Stud Fauna Curaçao the Hague 50:56-75

Stock JH (1992) A new species of Ingolfiella (Crustacea, Amphipoda, Ingolfiellidea) from mixohaline waters in Madeira. Bocagiana 159:1-11

Vonk R, Sanchez E (1991) A new marine interstitial ingolfiellid (Crustacea, Amphipoda, Ingolfiellidea) from Tenerife and Hierro. Hydrobiologia 223:293-299

Vonk R, Schram FR (2003a) Ingolfiellidea (Crustacea, Malacostraca, Amphipoda): a phylogenetic and biogeographic analysis. In: Vonk R (eds): Explorations of the systematics and deep history of stygobiont amphipods. Amsterdam. Academisch Proefschrift, pp 43-49

Vonk R, Schram FR (2003b) Ingolfiellidea (Crustacea, Malacostraca, Amphipoda): a phylogenetic and biogeographic analysis. Contrib Zool 72:39-73 